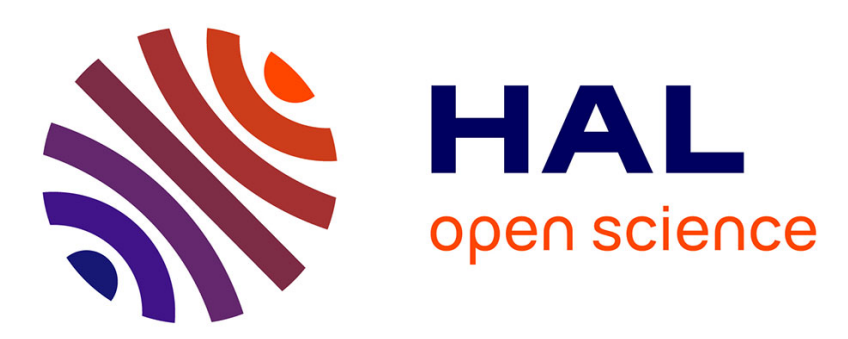

\title{
A New Topology for Induction Heating System with PM Excitation: Electromagnetic Model and Experimental Validations
}

Hakim Bensaidane, Thierry Lubin, Smail Mezani, Youcef Ouazir, Abderrezak Rezzoug

\section{To cite this version:}

Hakim Bensaidane, Thierry Lubin, Smail Mezani, Youcef Ouazir, Abderrezak Rezzoug. A New Topology for Induction Heating System with PM Excitation: Electromagnetic Model and Experimental Validations. IEEE Transactions on Magnetics, 2015, 12 p. 10.1109/TMAG.2015.2442515 . hal01164393

\section{HAL Id: hal-01164393 https://hal.science/hal-01164393}

Submitted on 16 Jun 2015

HAL is a multi-disciplinary open access archive for the deposit and dissemination of scientific research documents, whether they are published or not. The documents may come from teaching and research institutions in France or abroad, or from public or private research centers.
L'archive ouverte pluridisciplinaire HAL, est destinée au dépôt et à la diffusion de documents scientifiques de niveau recherche, publiés ou non, émanant des établissements d'enseignement et de recherche français ou étrangers, des laboratoires publics ou privés. 


\title{
A New Topology for Induction Heating System with PM Excitation: Electromagnetic Model and Experimental Validations
}

\author{
Hakim Bensaidane, Thierry Lubin, Smail Mezani, Youcef Ouazir and Abderrezak Rezzoug
}

\begin{abstract}
This paper presents a new structure of an induction heater for aluminium parallelepiped workpiece. The studied device uses a magnetic field created by a permanent magnets (PM) inductor (Halbach inductor) in which the conducting workpiece is subjected to a linear oscillatory motion with alternating velocity. An analytical electromagnetic model is developed to find the induced heating power in the workpiece. To consider the transverse edge effect, an analytical corrected model is also presented. The most important results obtained by these models are verified experimentally on a prototype.
\end{abstract}

Index Terms-, analytical model, oscillatory linear motion, permanent magnet, transverse edge effect.

\section{INTRODUCTION}

$\mathrm{I}_{\mathrm{a}}^{\mathrm{n}}$ nduction heating of non magnetic conducting materials like aluminium or copper before their extrusion or forming is widely used by many industrial processes. The principle and possibilities of realization of this heating process use since years two technological solutions [1].

Firstly, the conducting object is exposed to a variable magnetic induction produced by AC winding, generally called conventional induction heaters. The drawback of this technique is its poor efficiency which is about $50 \%$ [2], [3]. Thus, only half of the total input ac power is transformed into useful heat in the workpiece, the remaining $50 \%$ is lost in the ac copper winding. This requires water cooling to keep the winding at a reasonable working temperature (typically $\left.100^{\circ} \mathrm{C}\right)$.

Secondly, the conducting object is rotated and subjected to a space varying high DC magnetic field created by high temperature superconducting (HTS) coils. Efficiency in excess of $90 \%$ can theoretically be obtained [2], [3]. This very promising technology is costly (because of the high cost of the HTS wires) and requires typical cooling systems (called cryocoolers) to keep the HTS winding at its normal operating temperature (typically between 20 and 30 Kelvin).

More recently, a new induction heating concept using a permanent magnets system has been proposed [4]-[7]. Their

Manuscript received November 17, 2014.

H. Bensaidane and Y. Ouazir are with the University of science and technology (USTHB), BP N³2 El Alia Bab Ezzouar, Algiers, Algeria (email: hakimbensaidane@yahoo.fr and youazir@yahoo.fr).

T. Lubin, S. Mezani and A. Rezzoug are with GREEN-Université de Lorraine, Faculté des Sciences et Technologies, BP 239, 54506, Vandouvrelès-Nancy, France (e-mail: Thierry.Lubin@univ-lorraine.fr, Smail.Mezani@univ-lorraine.fr and Abderrezak.Rezzoug@univ-lorraine.fr). increasingly high performances make them a promising solution to develop a heater device of conducting materials. In this topology, a permanent magnets inductor produces a static magnetic field and the material to be heated is subjected to rotation. This technology is currently at the research step. Mach, Karban and al. [6], [7] realized a laboratory prototype where the heated object is in rotation in a static magnetic field generated by a permanent magnets inductor. The efficiency of this heater is about $85 \%$ [7]. The major constraint of this technology is the permanent magnets remanence degradation with the temperature. It requires a high-performance thermal insulation to keep the magnets within their maximum operating temperature.

When the heating system is intended for conducting materials extrusion ("in-heart heating" application), a uniform distribution of induced currents with a large skin depth is required to obtain an homogeneous temperatures, which is suitable for press-forming operation in industrial heating process. Then, the use of low velocities is necessary to achieve large skin depth.

In this paper, we analyse an original induction heater for aluminium parallelepiped workpiece using permanent magnets inductor. In this topology, the parallelepiped workpiece is subjected to a low oscillatory linear motion inside a static magnetic field produced by a Halbach inductor. In order to size eddy current devices, analytical models, when available, are the preferred tools of analysis [8]-[12]. We propose here a new analytical electromagnetic model to find the induced power in the workpiece. A corrected model which takes into account the transverse edge effect is also introduced to improve the accuracy of the results. The analytical findings are validated through finite element computations. An experimental prototype has been built to demonstrate the effectiveness of the proposed heating solution. Many measurements have been carried out showing the validity of the proposed analytical model.

\section{INDUCTION HEATER PROTOTYPE}

An induction heater prototype with linear motion has been designed and built. The static magnetic field is created by a quasi-Halbach permanent magnets arrangement. The aluminium workpiece moves at a linear oscillatory velocity. A controlled velocity drive with rotary motor is converted to a linear motion using a crank rod system. 


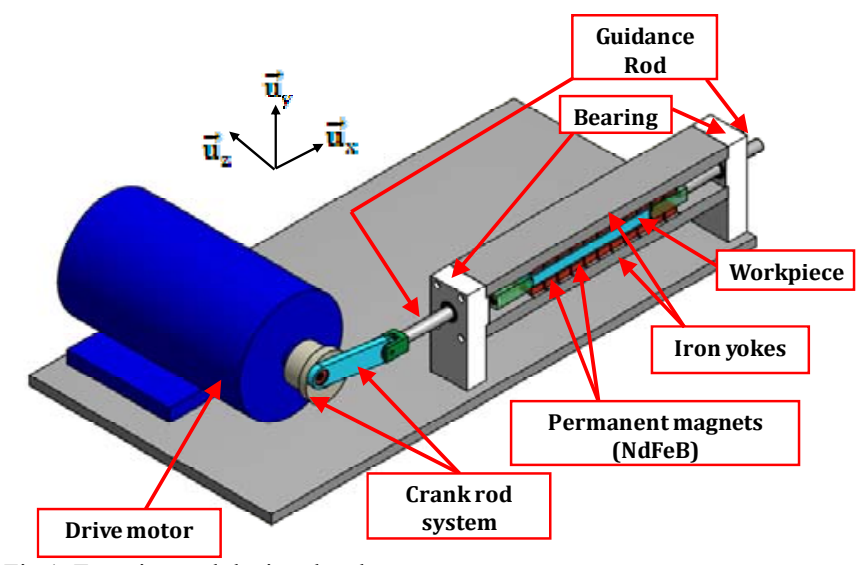

Fig.1. Experimental device sketch

\section{A. Experimental device description}

The heating demonstrator comprises two permanent magnets quasi-Halbach arrays glued on iron yokes to form two inductors. The workpiece to be heated has a $200 \mathrm{~mm}$ length, a $50 \mathrm{~mm}$ width and $15 \mathrm{~mm}$ thickness. It is placed between these two inductors. This workpiece is subjected to an alternating linear motion. The motion creates induced currents which dissipate a heating power by Joule effect. A schematic view of the experimental device is shown in Fig. 1.

\section{B. Permanent magnets inductor}

Eleven NdFeB magnets blocks are glued on iron yokes using an epoxy resin. Each block has a $50 \mathrm{~mm}$ length, $20 \mathrm{~mm}$ width and $10 \mathrm{~mm}$ thickness $(50 \mathrm{~mm} \times 20 \mathrm{~mm} \times 10 \mathrm{~mm})$. A gap of 2 $\mathrm{mm}$ separates the magnets so the total length of the magnets array is $240 \mathrm{~mm}$.

Obviously, a lower gap increases the flux density created by the inductor. However, it was technically more convenient to take a $2 \mathrm{~mm}$ gap to simplify the bonding of the PMs on the iron yokes. The iron yoke is made from an E24 grade steel and has $400 \mathrm{~mm}$ length, $60 \mathrm{~mm}$ width and $20 \mathrm{~mm}$ thickness. Figure 2 illustrates the permanent magnets inductor. The remanent flux density of the permanent magnets is of $1.21 \mathrm{~T}$ with a maximum operating temperature of $180{ }^{\circ} \mathrm{C}(\mathrm{N} 35 \mathrm{UH}$ grade $)$.

\section{Drive system}

The oscillatory linear motion of the workpiece is obtained by transformation of rotary motion generated by an induction motor as shown in Fig. 3. This transformation is obtained via a mechanical assembly connecting a crank-rod system to the drive motor shaft.

The mathematical model associated to the crank-rod system allows analytical expressions of the workpiece displacement and its velocity. Let us consider the following notations, Fig.3

- OB is the crank radius, $R_{m}=25 \mathrm{~mm}$. Its rotational velocity is $\Omega$ such that $\gamma=\Omega t$ is the rotation angle;

- $\quad \mathrm{AB}$ is the rod length, $L_{b}=110 \mathrm{~mm}$.

The relation which gives the $x$ coordinate vs. time $\mathrm{t}$ is then

$$
x(t)=R_{m}\left(1-\cos (\Omega t)+\frac{1}{2} \frac{R_{m}}{L_{b}} \sin ^{2}(\Omega t)\right)
$$

The workpiece linear velocity is given by

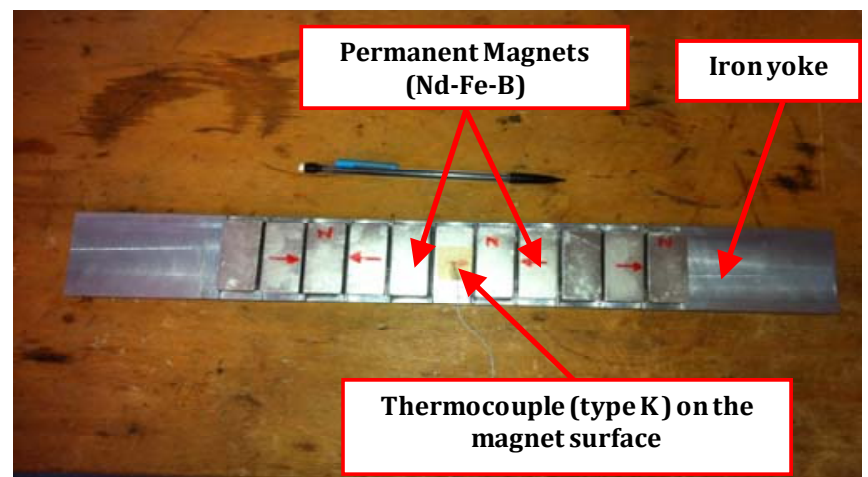

Fig.2. Halbach permanent magnets inductor

$$
v(t)=R_{m} \Omega\left(\sin (\Omega t)+\frac{1}{2} \frac{R_{m}}{L_{b}} \sin (2 \Omega t)\right)
$$

The time period of the oscillatory linear velocity is defined as $T=2 \pi / \Omega$.

The drive motor is a 3-phase, 8- poles induction motor rated at $1.1 \mathrm{~kW}, 700 \mathrm{rpm}$. This motor is supplied using a 3-phase converter with a constant flux control.

To provide the linear guidance of the workpiece, linear ball bearings from SKF (LBCR16A) have been used. The characteristics of this linear ball bearing are defined as:

- Inner diameter $16 \mathrm{~mm}$

- Outer diameter $26 \mathrm{~mm}$

- Total length $36 \mathrm{~mm}$

- Ball number circuits 06

- Masse $0.021 \mathrm{~kg}$

- Load capacity in dynamic state $1500 \mathrm{~N}$

- Load capacity in static state $1290 \mathrm{~N}$

\section{Instrumentations and measurement protocols}

In this section, we present the various measurements carried out on the realised induction heater prototype. The workpiece displacement is measured by an optical position sensor OD2N85W20A0 from SICK Sensor Intelligence with the following characteristics

- High resolution $10 \mu \mathrm{m}$;

- Measurement frequency $2 \mathrm{kHz}$;

- Response time $1 \mathrm{~ms}$

- $\quad$ Linearity $\pm 40 \mu \mathrm{m}$

- Measuring range (65mm-105mm)

The air gap flux density is measured by a gaussmeter GM08 based on Hall Effect from HIRST Magnetic Instruments with the following characteristics
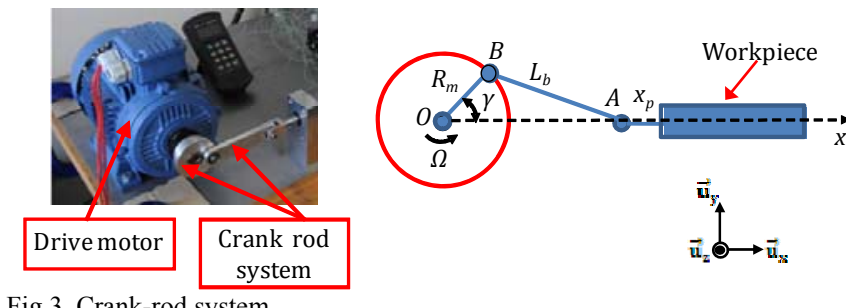

Fig.3. Crank-rod system 
- Frequency $15 \mathrm{~Hz}-10 \mathrm{kHz}$

- Operating temperature $0^{\circ} \mathrm{C}-50^{\circ} \mathrm{C}$

- Resolution $1 \mathrm{mT}$

- Wide measuring range (0T-3T)

- $\quad$ Used for AC/DC magnetic field

\section{Heating power determination:}

Using the following experimental protocol, the heating power is measured indirectly:

The $n$-th experiment deals with the mechanical speed $\Omega_{\mathrm{n}}$. For all experiments the ratio $\mathrm{V}_{\mathrm{n}} / \mathrm{f}_{\mathrm{n}}$ is held constant (constant air gap flux control).

The experimental process is divided in two main parts:

Part a: Only the workpiece is linked to the electromechanical system while the two magnets inductors are removed. The electrical values $\left(\mathrm{P}_{0 \mathrm{n}}, \mathrm{V}_{0 \mathrm{n}}, \mathrm{f}_{0 \mathrm{n}}, \mathrm{I}_{0 \mathrm{n}}\right)$ are measured for different speed values $\Omega_{\mathrm{n}}$.

Part b: The two magnets inductors are now placed above and below the workpiece to be heated. The electrical values $\left(\mathrm{P}_{1 \mathrm{n}}\right.$, $\left.\mathrm{V}_{1 \mathrm{n}}, \mathrm{f}_{1 \mathrm{n}}, \mathrm{I}_{1 \mathrm{n}}\right)$ are measured for different speed values $\Omega_{\mathrm{n}}$.

For the same mechanical speed the mechanical losses are the same $\left(\mathrm{p}_{\mathrm{m} 0 \mathrm{n}}=\mathrm{p}_{\mathrm{m} 1 \mathrm{n}}=\mathrm{p}_{\mathrm{mn}}\right)$.

During the whole experimental study, the input power of the induction motor remains far from the nominal operating power (around $130 \mathrm{~W}$ compared to $1100 \mathrm{~W}$ ). So the slip is very small compared to the unity in any case and the ratio $\mathrm{Rr} / \mathrm{s}_{\mathrm{n}}$ is so high to be considered as infinite (open circuit). In another hand, to obtain the same speed $\Omega_{\mathrm{n}}$ in charge only a slight increase of the frequency $f_{n}$ is necessary and consequently the iron losses, which depend on the flux and frequency, could be considered, with a good approximation, as constant $\left(\mathrm{p}_{\mathrm{fs} 0 \mathrm{n}} \sim \mathrm{p}_{\mathrm{fs} \ln }=\mathrm{p}_{\mathrm{fsn}}\right)$.

Because the armature flux remains constant and $f_{0 n} \sim f_{1 n}$, for a given mechanical speed $\Omega_{\mathrm{n}}$, the rotor current remains approximately negligible as well as the rotor losses $\mathrm{p}_{\mathrm{jr} 0 \mathrm{n}} \sim$ $\mathrm{p}_{\mathrm{jr} 1 \mathrm{n}} \sim 0$.

The balance of power, with $\mathrm{P}$ the heating power, is:

Case a: $\left(1-\mathrm{s}_{\mathrm{n}}\right)\left[\mathrm{P}_{0 \mathrm{n}}-\mathrm{p}_{\mathrm{fsn}}-\mathrm{p}_{\mathrm{js} 0 \mathrm{n}}\right] \sim\left[\mathrm{P}_{0 \mathrm{n}}-\mathrm{p}_{\mathrm{fsn}}-\mathrm{p}_{\mathrm{js} 0 \mathrm{n}}\right]=\mathrm{p}_{\mathrm{jrn}}+\mathrm{p}_{\mathrm{m} 0 \mathrm{n}}$

Case b: $\left(1-\mathrm{s}_{\mathrm{n}}\right)\left[\mathrm{P}_{1 \mathrm{n}}-\mathrm{p}_{\mathrm{fsn}}-\mathrm{p}_{\mathrm{js} 1 \mathrm{n}}\right] \sim\left[\mathrm{P}_{1 \mathrm{n}}-\mathrm{p}_{\mathrm{fsn}}-\mathrm{p}_{\mathrm{js} 1 \mathrm{n}}\right]=\mathrm{p}_{\mathrm{jrn}}+\mathrm{p}_{\mathrm{m} 0 \mathrm{n}}+\mathrm{P}$

By difference we obtain: $P=\left[\left(P_{1 n}-p_{j s 1 n}\right)-\left(P_{0 n}-p_{j s 0 n}\right)\right]$

Another remark is that, when the power input is far from the nominal one, the armature current varies slightly meanwhile the power factor varies significantly, so: $\mathrm{P} \sim \mathrm{P}_{1 \mathrm{n}}-\mathrm{P}_{0 \mathrm{n}}$

We note that the variation of workpiece electrical conductivity with temperature can be determined. Indeed, type-K thermocouples are placed on the workpiece surface, so the electrical conductivity is evaluated by

$$
\sigma(\theta)=\frac{1}{\rho(\theta)} \text { with } \rho(\theta)=\rho_{0}\left(1+\alpha\left(\theta-\theta_{\text {ref }}\right)\right)
$$

$\rho_{0}$ is the aluminium resistivity at a reference temperature $\theta_{\text {ref }}=20^{\circ} \mathrm{C}, \alpha$ the aluminium thermal coefficient, and $\theta$ the operating temperature. The workpiece electrical conductivity values evaluated in this test will be used in the electromagnetic model developed in sections III and IV (more

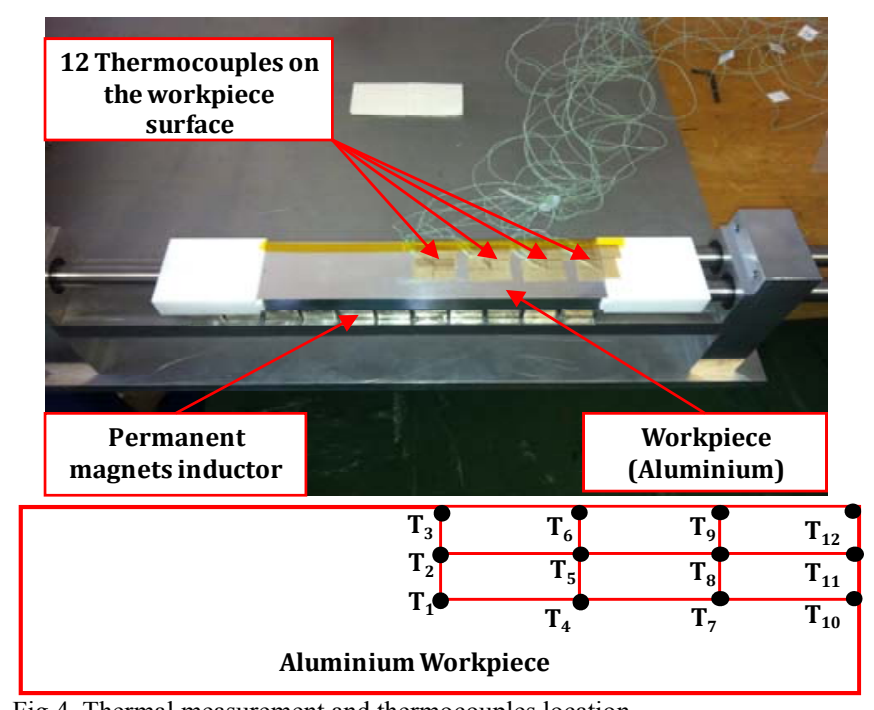

Fig.4. Thermal measurement and thermocouples location

specifically for the heating power evaluation (C.9) which strongly depends on the temperature).

For the thermal measurement, while exploiting the geometry symmetries of the system, 12 thermocouples (type K Nickelchromium from LABFACILITY Temperature \& Process Technology) are placed on a quarter surface of the workpiece. The thermocouple characteristics are:

- Temperature range measurement $-50^{\circ} \mathrm{C}$ to $+250^{\circ} \mathrm{C}$;

- Patch dimensions $25 \mathrm{~mm} \times 20 \mathrm{~mm}$;

The thermocouple location in the device is shown in Fig. 4. We note that the temperature of the permanent magnets is also measured by a thermocouple placed at its surface (to verify that the PM operating temperature is lower than its maximum limit). A data acquisition system "Midi Logger GL220" from GRAPHTEC Technology enables temperature readings at regular time intervals. The general view of the realized induction heater is shown in Fig. 5.

\section{EleCtromagnetic MODEL}

\section{A. Description}

Figure 6 shows a 2D cross section of the studied induction heater geometry. It consists of two inductors each one made of quasi-Halbach permanent magnets array. The aluminium workpiece is placed between the two inductors and oscillates linearly. The workpiece linear displacement in the static magnetic field generates induced currents that produce heating power in it. Low linear velocity is used to reach a large skin depth as to obtain a homogeneous distribution of the heating power and temperature. This is a mandatory requirement before the press-forming step of the aluminum workpiece. The physical and geometrical parameters of the studied device are given in Table I.

The following assumptions are adopted to establish the electromagnetic analytical model for the studied induction heater

- 2D plane approximation, so the device has an infinite length along $\mathrm{z}$;

- Low linear velocity is considered; 
- the reaction field due to the eddy currents $(\partial \boldsymbol{A} / \partial t$ term) in the workpiece is neglected;

- The longitudinal (along $x$ ) edge effects are neglected;

- The electrical conductivity of permanent magnets is considered null;

- The permeability of the iron yokes is large enough to be considered as infinite.

\section{B. Field source model}

We consider that the magnetization has an infinite length and is periodic along the $x$-direction (longitudinal direction). In the Cartesian coordinate system, the magnetization $\boldsymbol{M}$ is written as

$$
\boldsymbol{M}=M_{x}(x) \mathbf{u}_{\boldsymbol{x}}+M_{y}(x) \mathbf{u}_{\boldsymbol{y}}
$$

where $M_{x}$ and $M_{y}$ denote the components of $\boldsymbol{M}$ in the $x$ and $y$ directions respectively. Figure 7 shows the distribution of $M_{x}$ and $M_{y}$, which may be expanded into a Fourier series. Using the complex notation, the magnetization components can be written as (see Appendix $A$ )

$$
\begin{aligned}
& M_{x}(x)=\mathfrak{R}\left[\sum_{n=1,3,5, \ldots}^{\infty} M_{x n} e^{j n k x}\right] \\
& M_{y}(x)=\mathfrak{R}\left[\sum_{n=1,3,5, \ldots}^{\infty}-j M_{y n} e^{j n k x}\right]
\end{aligned}
$$

where $\mathfrak{R}$ denotes the real part of a complex number.

As it can be seen from Fig. 7, the spatial period along $x$ of the magnetization distribution is $\tau=2(a+b)+4 e_{g}=88 \mathrm{~mm}$.

\section{Diffusion equation}

The geometric symmetry of the device relative to the axis $x$ allows to analyse a general multiregion problem shown in Fig.8. The whole space is divided into three regions

- Region 1 corresponds to the conducting workpiece;

- $\quad$ Region 2 corresponds to the air gap;

- Region 3 corresponds to the permanent magnets.

TABLE I

PHYSICAL AND GEOMETRICAL PARAMETERS OF THE STUDIED INDUCTION HEATER

\begin{tabular}{lll}
\hline \hline Symbol & \multicolumn{1}{c}{ Quantity } & \multicolumn{1}{c}{ Value } \\
\hline $2 y_{l}$ & Conducting workpiece thickness & $15 \mathrm{~mm}$ \\
$L_{p}$ & Conducting workpiece length & $200 \mathrm{~mm}$ \\
$Z_{p}$ & Conducting workpiece width & $50 \mathrm{~mm}$ \\
$d$ & Air-gap & $3 \mathrm{~mm}$ \\
$e$ & Permanent magnets thickness & $10 \mathrm{~mm}$ \\
$a$ & Along $x$ magnetized PM width & $20 \mathrm{~mm}$ \\
$b$ & Along $y$ magnetized PM width & $20 \mathrm{~mm}$ \\
$Z_{a}$ & Permanent magnets axial length & $50 \mathrm{~mm}$ \\
$e_{g}$ & Distance between two magnets & $2 \mathrm{~mm}$ \\
$y_{c}$ & Iron yoke thickness & $20 \mathrm{~mm}$ \\
$L_{c}$ & Iron yoke length & $400 \mathrm{~mm}$ \\
$Z_{c}$ & Iron yoke width & $60 \mathrm{~mm}$ \\
$v(t)$ & Oscillatory linear velocity & variable \\
$v_{m a x}$ & Velocity peak value & variable \\
$B_{r}$ & Remanent flux density of magnet & $1.21 \mathrm{~T}$ \\
$\mu_{r a}$ & Relative magnetic permeability of magnet & 1.05 \\
$\sigma$ & Aluminium workpiece conductivity at $20^{\circ} \mathrm{C}$ & $33 \times 10^{6} \mathrm{Sm}^{-1}$ \\
$\alpha$ & Aluminium thermal coefficient & $3.9 \times 10^{-3} \mathrm{~K}^{-1}$ \\
\hline
\end{tabular}

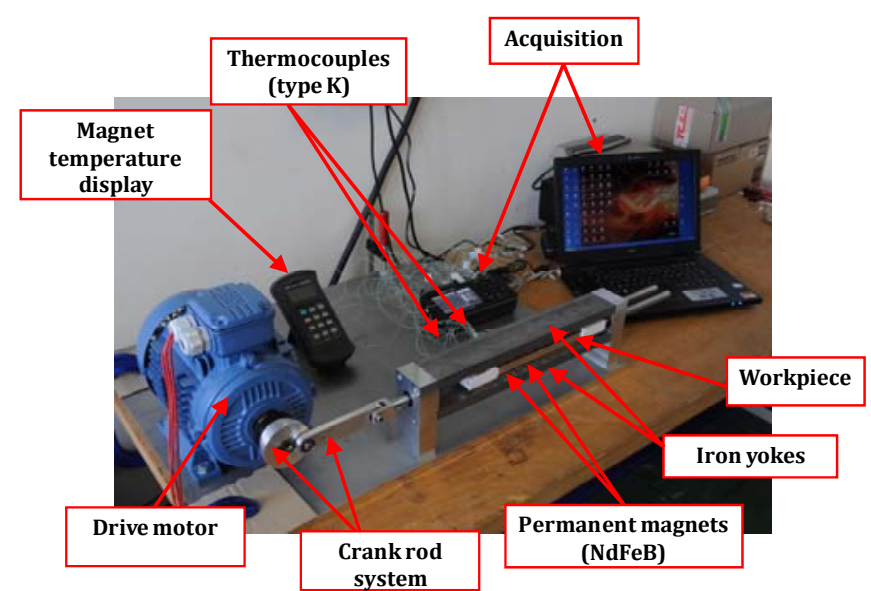

Fig.5. Induction heater prototype, drive system, measurements and data acquisition

By considering the linear oscillatory motion (linear alternating velocity) of the workpiece, the electromagnetic behaviour of the system is described as follow.

$$
\begin{aligned}
& \nabla . B=0 \\
& \nabla \times H=J
\end{aligned}
$$

The above equations lead to solve the problem, with magnetic vector potential $\boldsymbol{A}$ formulation such as

$$
\boldsymbol{B}=\boldsymbol{\nabla} \times \boldsymbol{A}
$$

Furthermore, we neglect the reaction field due to $\partial \boldsymbol{A} / \partial t$ term so only velocity eddy currents remain in the wokpiece. This assumption is realistic because of the low value of the workpiece velocity. Moreover, the validity of this approximation will be a posteriori checked through the finite element computations. The constitutive laws in the workpiece are defined as follows

$$
\begin{aligned}
& \boldsymbol{J}=\sigma \boldsymbol{v}(\boldsymbol{t}) \times \boldsymbol{B} \\
& \boldsymbol{B}=\mu_{0} \boldsymbol{H}
\end{aligned}
$$

In the magnets we can write

$$
\boldsymbol{B}=\mu_{\boldsymbol{a}} \boldsymbol{H}+\boldsymbol{B}_{\boldsymbol{r}}
$$

where $\mu_{\boldsymbol{a}}=\mu_{0} \mu_{\boldsymbol{r} \boldsymbol{a}}$ is the permanent magnet permeability.

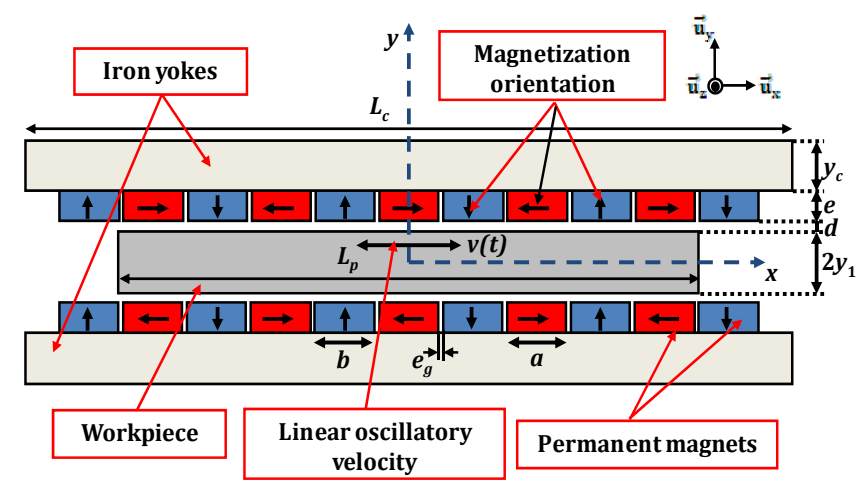

Fig.6.Induction heater geometry with permanent magnets inductor and linear oscillatory motion 


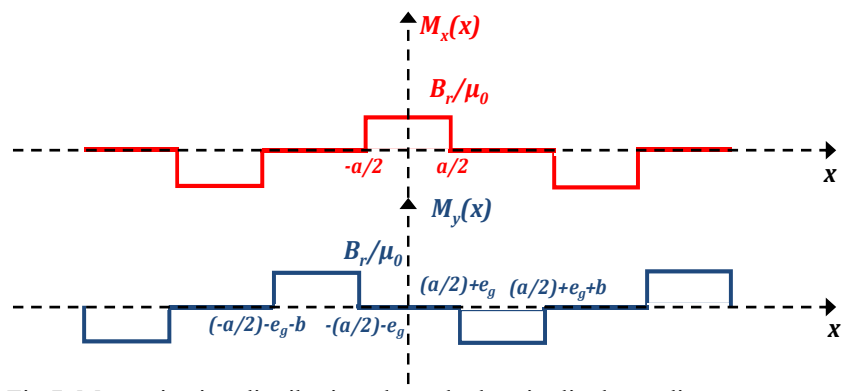

Fig.7. Magnetization distribution along the longitudinal coordinate $x$

We neglect the longitudinal and transversal edge effects; hence a $2 \mathrm{D}$ model is used. The magnetic vector potential in each region presents only one component in the $z$-direction and depends only on the $x$ and $y$ coordinates.

From (7) to (12), the partial differential equations (PDE) to solve in the different regions are derived.

- In region 1 (workpiece):

The magnetic vector potential is noted $A_{1}$. The workpiece is oscillating in the $x$ direction at a speed noted $v(t)$. The PDE to solve in the conducting workpiece is then

$$
\frac{\partial^{2} A_{1}}{\partial x^{2}}+\frac{\partial^{2} A_{1}}{\partial y^{2}}=\sigma \mu_{0} v(t) \frac{\partial A_{1}}{\partial x}
$$

- In region 2 (air gap)

The magnetic vector potential is noted $A_{2}$. The PDE to solve is

$\frac{\partial^{2} A_{2}}{\partial x^{2}}+\frac{\partial^{2} A_{2}}{\partial y^{2}}=0$

- In region 3 (permanent magnets inductor)

The magnetic vector potential is noted $A_{3}$. The PDE to solve is

$$
\frac{\partial^{2} A_{3}}{\partial x^{2}}+\frac{\partial^{2} A_{3}}{\partial y^{2}}=-\mu_{0} \frac{\partial M_{y}}{\partial x}
$$

\section{Magnetic vector potential expressions}

Due to the periodicity of the field source, the solution of the magnetic vector potential in region $i(i=1,2,3)$ can be written as

$$
A_{i}(x, y)=\sum_{n=1,3,5, \ldots}^{\infty} A_{i}(y) \cos \left(n k x+\varphi_{n i}(y)\right)
$$

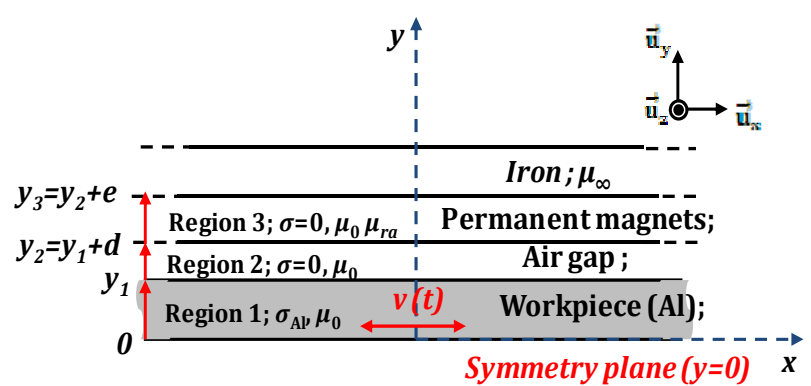

Fig.8. Multiregion analysis problem by using the complex notation, (16) is rewritten as

$$
A_{i}(x, y)=\Re\left\{\sum_{n=1,3,5, \ldots}^{\infty} \bar{A}_{i}(y) e^{j n k x}\right\}
$$

The general solution in each region is given in Appendix $B$.

\section{E. Eddy-Current Expression}

The induced current density in the aluminium workpiece (region 1), derived from (10), is rewritten as

$$
\boldsymbol{J}_{1}(x, y, t)=\sigma \boldsymbol{v}(t) \times \boldsymbol{\nabla} \times \boldsymbol{A}_{1}=-\sigma v(t) \frac{\partial A_{1}(x, y)}{\partial x}
$$

which gives using the complex notation

$J_{1}(x, y, t)=\Re\left[\sum_{n=1,3,5, \ldots}^{\infty}-j n k \sigma v(t) \bar{A}_{1}(y) e^{j n k x}\right]$

\section{F. Heating Power Expression}

The induced power density in the aluminium workpiece is expressed as

$p(x, y, t)=\frac{J_{1}^{2}(x, y, t)}{\sigma}$

Therefore, the induced power in the aluminium workpiece is

$$
P(t)=\int_{\frac{-L_{p}}{2}}^{\frac{L_{p}}{2}} \int_{-y_{1}}^{y_{1}} \frac{\frac{Z_{p}}{2}}{\frac{Z_{p}}{2}} \frac{J_{1}^{2}(x, y, t)}{\sigma} d x d y d z
$$

After integration, we obtain the analytical expression of the induced heating power in the conducting workpiece.

$$
P(t)=\sum_{n=1,3,5, \ldots}^{\infty} 4 Z_{p} \sigma v(t)^{2}(n k)^{2} a_{1 n}^{2} M F
$$

with : $\quad M=\frac{1}{\bar{\lambda}_{n_{1}}+\bar{\lambda}_{n_{1}}^{*}}\left[\sinh \left(\left(\bar{\lambda}_{n_{1}}+\bar{\lambda}_{n_{1}}^{*}\right) y_{1}\right)\right]+$

$$
\frac{1}{\bar{\lambda}_{n_{1}}-\bar{\lambda}_{n_{1}}^{*}}\left[\sinh \left(\left(\bar{\lambda}_{n_{1}}-\bar{\lambda}_{n_{1}}^{*}\right) y_{1}\right)\right]
$$$$
\text { and } \quad F=\frac{1}{2}\left[L_{p}+\frac{\sin \left(n k L_{p}\right) \cos \left(2 \varphi_{n_{1}}\left(y=y_{1}\right)\right)}{n k}\right]
$$

where $\varphi_{n_{1}}\left(y=y_{1}\right)$ is the argument of $\bar{A}_{1}\left(y=y_{1}\right)$ and $\bar{\lambda}_{n_{1}}=\sqrt{n^{2} k^{2}+j n k \sigma \mu_{0} v(t)}$. The average induced heating power is obtained by

$$
P_{A v g}=\frac{2}{T} \int_{\frac{T}{2}} P(t) d t
$$

with $T=2 \pi / \Omega$ is the time period of the oscillatory linear velocity. 


\section{TRANSVERSE EdGE EFFECT}

As in rotating or linear motors, the consideration of the edge effects is important for predicting the performances. The studied heating device has a finite length along $\mathrm{x}$ and a finite width along $\mathrm{z}$ which create edge effects. The constructed heater has strong magnetic edge effects that need to be taken into account in the developed model. In this section, we only treat the transverse edge effect (finite width along $z$-direction) [13]-[17].

In the electromagnetic model previously developed, the eddy currents density had only one component according to $z$ direction, Fig. 9(a). However, eddy currents distribution in the workpiece also exhibits a longitudinal component along the $x$ direction, Fig. 9(b). Consequently the induced power heating is not correctly evaluated by our model.

In order to improve the model accuracy, we present here an approach based on the correction of the workpiece resistivity to account for edge effect. A similar approach can be found in [13]. So we give here the main assumptions and the useful expression to determine this correction coefficient. More details are included in appendix $\mathrm{C}$.

The starting point is to consider that the magnetic field has only one component along the $y$-direction. Under this condition, the analyzed problem is two-dimensional and treated in the $(x, z)$ plane (Fig. 10). The following assumptions are adopted

- The conducting workpiece has an infinite length along $\mathrm{x}$;

- The magnetic flux density, created by permanent magnets inductor, is supposed invariant along the $y$ direction. Moreover, this magnetic flux density will be periodically distributed along the $x$-direction and independent of $z$. Therefore, the attenuation near the edges is not considered;

- The reaction field due to the velocity eddy currents in the workpiece is neglected.

Therefore, the electric and magnetic quantities are

$$
\begin{aligned}
& \boldsymbol{J}=J_{x}(x, z, t) \boldsymbol{u}_{\boldsymbol{x}}+J_{z}(x, z, t) \boldsymbol{u}_{\boldsymbol{z}} \\
& \boldsymbol{H}=H_{y}(x, z, t) \boldsymbol{u}_{\boldsymbol{y}}
\end{aligned}
$$

The magnetic flux density, created by permanent magnets inductor is expressed by

$$
\boldsymbol{B}=\sum_{n=1,3,5, \ldots}^{\infty} \hat{B}_{n} \cos (n k x) \boldsymbol{u}_{\boldsymbol{y}}
$$

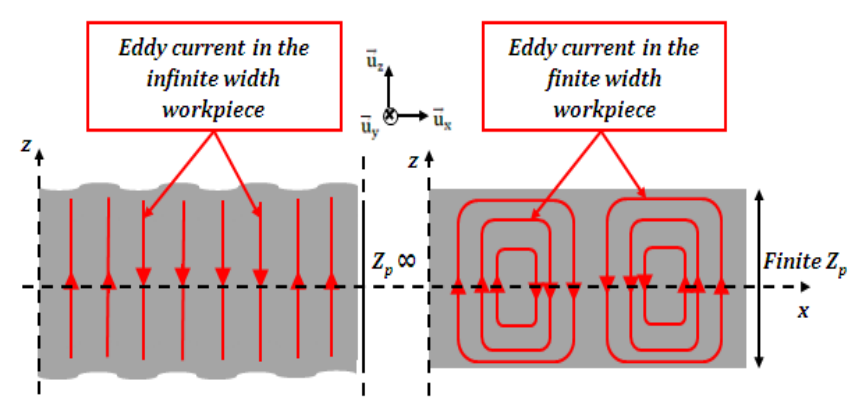

(a)

(b)

Fig.9. Eddy current distribution (a)-infinite width workpiece (b)-finite width workpiece

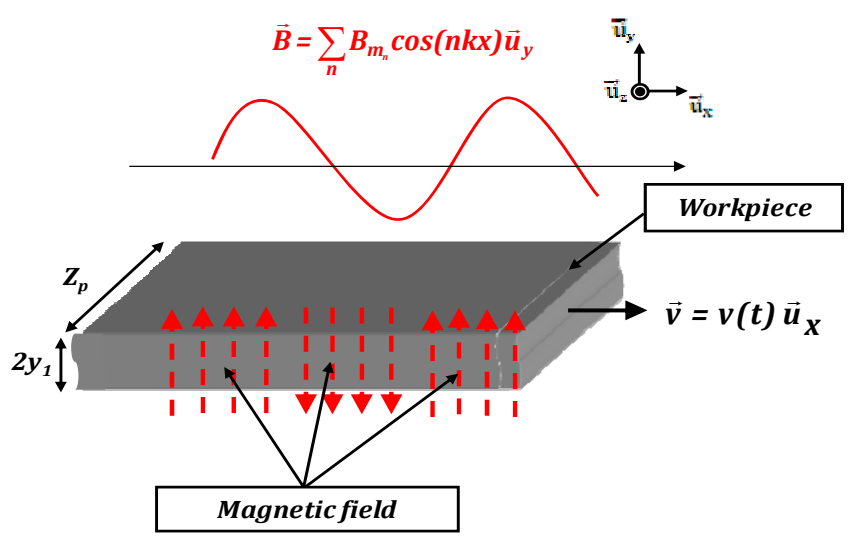

Fig.10. Geometrical model for analysing the transverse edge effect

with $k=\frac{2 \pi}{\tau}$ and $\hat{B}_{n}$ is the peak value of the flux density. It is evaluated using the previously developed model in the plan $\mathrm{y}=0$.

The PDE to solve for $H_{y}$ as state variable is then

$\frac{\partial^{2} H_{y}}{\partial x^{2}}+\frac{\partial^{2} H_{y}}{\partial z^{2}}=\sum_{n=1,3,5, . .}^{\infty} \sigma n k v(t) \hat{B}_{n} \sin (n k x)$

The magnetic field due to the PMs being periodic along $x$, one can use the complex notation such that $H_{y}$ is written as

$$
H_{y}(x, z, t)=\mathfrak{R}\left[\sum_{n=1,3,5, \ldots}^{\infty} \bar{H}_{y}(z, t) e^{j n k x}\right]
$$

Solving analytically (27) by separation of variables leads to the following form solution

$$
H_{y}(x, z, t)=\Re\left[\sum_{n=1,3,5 . .}^{\infty}\left(\bar{c}_{1 n} e^{n k z}+\bar{c}_{2 n} e^{-n k z}-j \frac{\sigma v(t) \hat{B}_{n}}{n k}\right) e^{j n k x}\right]
$$

From $H_{y}$, we deduce the following expressions for the eddy current components

$$
\begin{aligned}
& J_{x}(x, z, t)=\sum_{n=1,3,5, \ldots}^{\infty} \sigma v(t) \hat{B}_{n}\left(\frac{\sinh (n k z)}{\cosh \left(\frac{n k Z_{p}}{2}\right)}\right) \sin (n k x) \\
& J_{z}(x, z, t)=\sum_{n=1,3,5 \ldots}^{\infty} \sigma v(t) \hat{B}_{n}\left(1-\frac{\cosh (n k z)}{\cosh \left(\frac{n k Z_{p}}{2}\right)}\right) \cos (n k x)
\end{aligned}
$$

When we consider an infinite workpiece width only the $J_{z}$ component exists. The induced power heating created by $J_{z}$ is

$$
P_{0}(t)=\sum_{n=1,3,5 \ldots}^{\infty} P_{0}(n)
$$

where $P_{0}(n)$ is the power heating induced by the $n^{\text {th }}$ harmonic. It is given by 


$$
P_{0}(n)=2 y_{1} Z_{p} \sigma v(t)^{2} \hat{B}_{n}^{2}\left[\frac{1}{2} L_{p}+\frac{\sin \left(n k L_{p}\right)}{2 n k}\right]
$$

On the other hand when the workpiece has a finite width (with transverse edge effect), the induced power heating $P_{0}$ becomes $P$ which is expressed as (see appendix C)

$$
P(t)=\sum_{n=1,3,5, \ldots}^{\infty} k_{\text {corr }}(n) P_{0}(n)
$$

where

$$
k_{\text {corr }}(n)=1-\frac{\tau}{n \pi Z_{p}} \tanh \left(\frac{n \pi Z_{p}}{\tau}\right)
$$

can be seen as a correction factor of the electric conductivity for the $\mathrm{n}^{\text {th }}$ harmonic. Hence, replacing $\sigma$ by $k_{\text {corr }}(n) \sigma$ in the 2D model of section III allows the consideration of the transverse edge effect in evaluating the induced power heating. Note that the workpiece electrical conductivity $\sigma$ depends on the measured temperature as shown by the expression (3).

\section{RESUlts AND EXPERIMENTAL VALIDATION}

We present in this section the experimental results obtained by the various measurements carried out on the device. The experimental results are compared to the analytical ones as well as to the results obtained thanks to 3D finite-element model implemented in COMSOL-Multiphysics software. To perform the $3 \mathrm{D}$ finite element computations with COMSOL software, a 3D mesh of 841263 tetrahedral elements leading to solve a global algebraic system having 5360005 degrees of freedom is used. Obviously, the 3D models take into account all the edge effects which are not fully considered in the analytical model. The computation time in 3D FEM using work station (48Go (RAM), 2 processors with 16 core), is $196 \mathrm{~s}$, whereas the computing time of the proposed analytical model is about $1 \mathrm{~s}$ on desktop PC (3Go (RAM), Intel core duo).

\section{A. Mechanical position and speed}

Before comparing the electromagnetic performances, the first results concern the mechanical position of the workpiece generated by the crank rod system.

Figure 11 gives the displacement measured by the optical sensor for a peak value $v_{\max }=0.63 \mathrm{~m} / \mathrm{s}$ of the linear velocity. A satisfactory agreement is observed between the measured position and the calculated one obtained by the analytical expression (1). The corresponding linear velocity is illustrated on Fig. 12. We can observe that the linear velocity presents a sinusoidal waveform.

\section{B. Electromagnetic performances}

Figures 13 and 14 show the distribution of the flux density component $B_{y}$ along the longitudinal coordinate $x$ in the middle of the air-gap $\left(y=y_{1}+d / 2\right)$ for $z=0$ and $z=Z_{p} / 5=10 \mathrm{~mm}$ respectively. It can be seen that the theoretical predictions using the analytical and the 3D FEM models are in very good agreement compared to the experiments. The peak value of the flux density is about 0.6 T. At the middle of the air-gap, Fig.
15 shows the spatial distribution of the flux density component $B_{y}$ along $z$-direction with $x=(a+b) / 2+e_{g}$ (under a north pole). One can note that $B_{y}$ remains constant (approximately $0.6 \mathrm{~T}$ ) over $4 \mathrm{~cm}$ and decreases quickly on the remaining length of the magnet. We can notice that the measurements are in very good agreement compared to the 3D FEM.

In order to check the accuracy of the corrected analytical model, we have plotted in Figs 16 and 17 respectively the current density distributions $J_{x}$ and $J_{z}$. The plots are represented in an $(x, z)$ plan at the middle of the workpiece $(y=0)$ and the analytical results are compared to the ones issued from the 3D FEM model. It can be seen that the corrected analytical model which takes into account the finite width of the workpiece gives almost the same results as the 3D FE predictions. The results are slightly different on the longitudinal sides of the workpiece as the longitudinal edge effects are ignored in our analytical model. Nevertheless, these differences have a minor impact on evaluating the heating power.

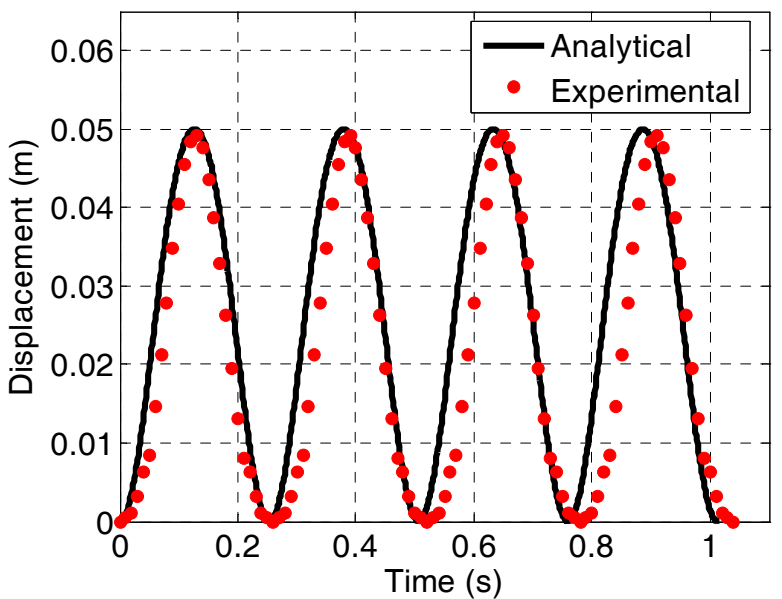

Fig.11. Linear displacement evolution versus time

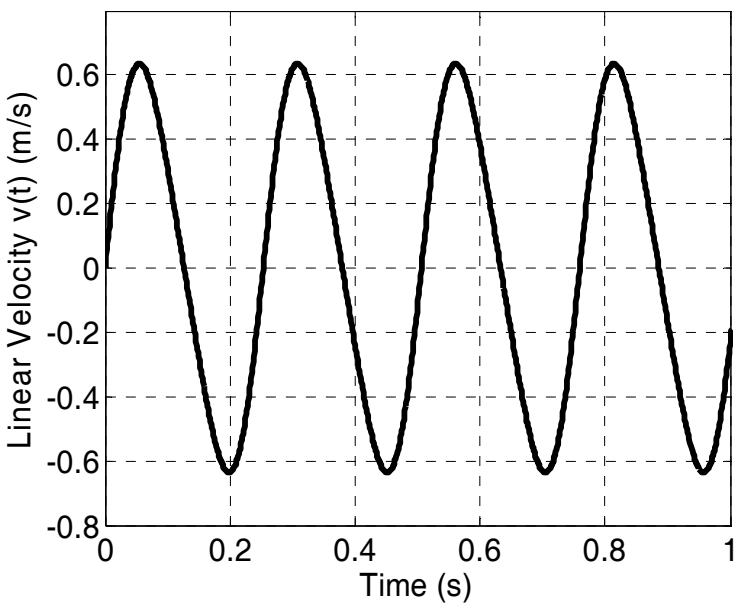

Fig.12. Linear velocity evolution versus time 


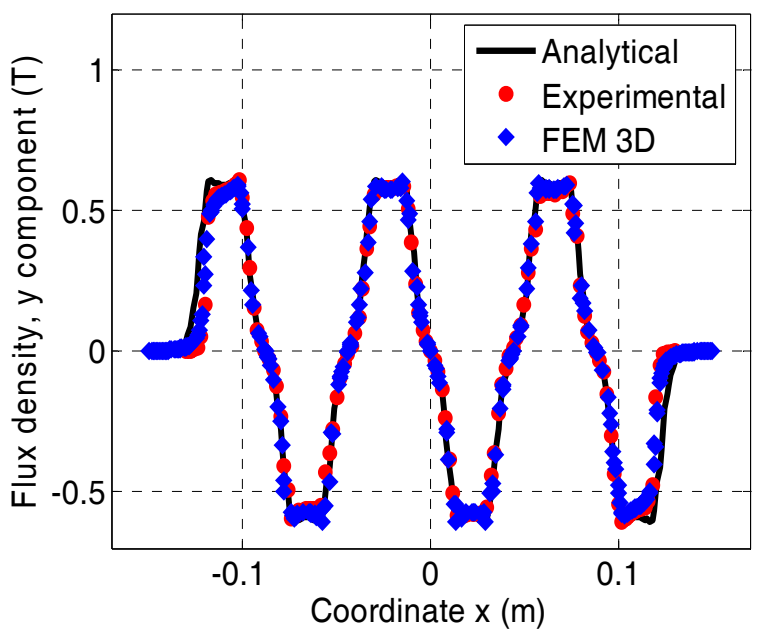

Fig.13. Flux density component $B_{y}$ versus longitudinal coordinate $x$ at the middle of the air-gap with $y=y_{1}+d / 2$ and $z=0$

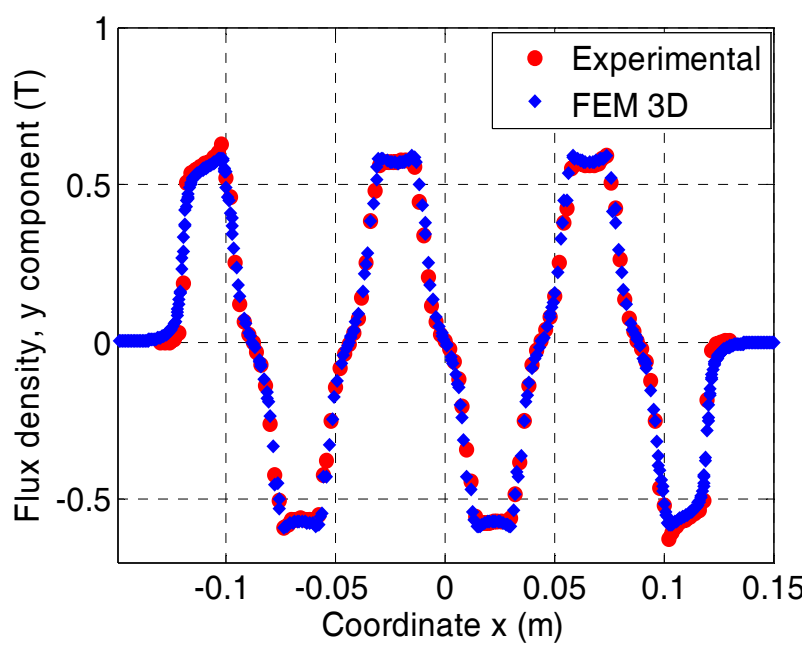

Fig.14. Flux density component $B_{y}$ versus longitudinal coordinate $x$ at the middle of the air-gap with $y=y_{1}+d / 2$ and $z=Z_{p} / 5$

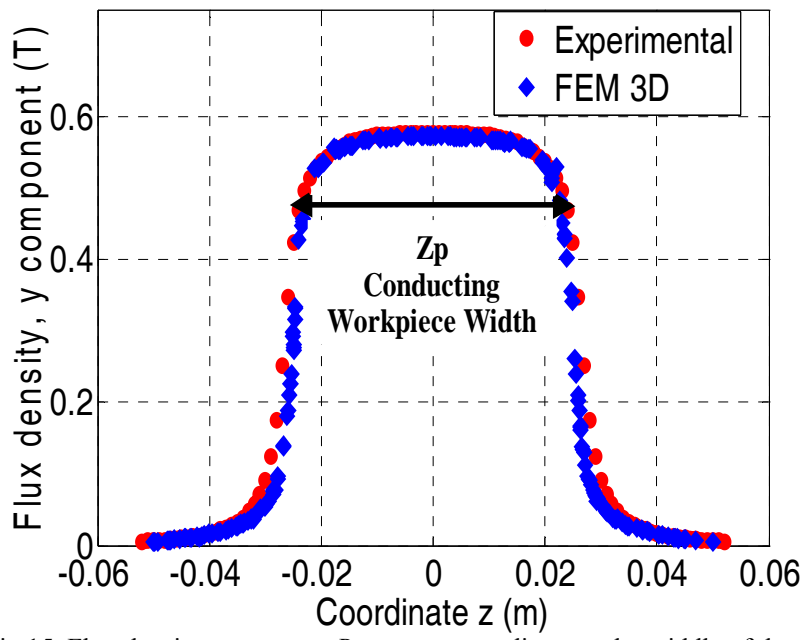

Fig.15. Flux density component $B_{y}$ versus $z$ coordinate at the middle of the airgap with $y=y_{1}+d / 2$ and $x=(a+b) / 2+e g$ (North Pole)

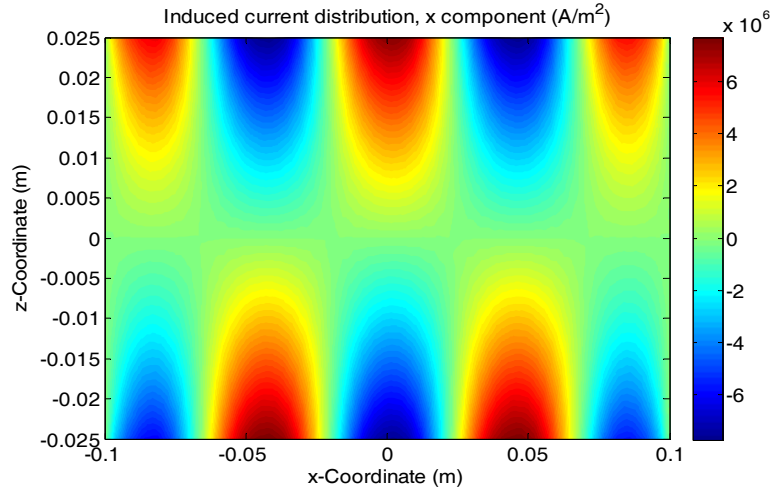

(a)

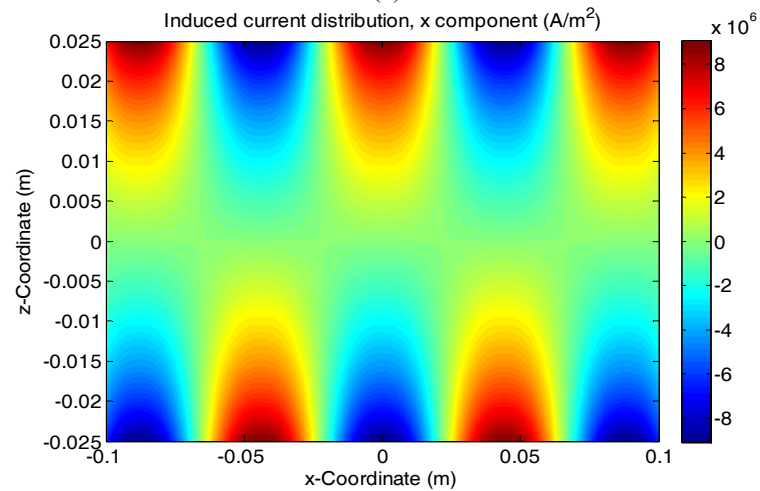

(b)

Fig.16. Induced current density distribution $J_{x}$ in $x z$ plane at the middle of the workpiece $(y=0)$ and $v_{\max }=1 \mathrm{~m} / \mathrm{s}$ : (a) 3D FEM, (b) Corrected analytical model

The average induced heating power in the conducting aluminum workpiece obtained for various peak values of the linear velocity $v_{\max }$ is given in Fig. 18 . These results have been obtained using the analytical expression (22) and compared with those obtained by 3D FEM and measured values. Under these conditions, we can observe that the analytical model overestimate the heating power. The relative difference reaches $150 \%$ at $v_{\max }=1.2 \mathrm{~m} / \mathrm{s}$. Consequently, the developed 2D model under the assumption of infinite conducting workpiece axial length fails to correctly predict the heating power.

As shown in Fig. 19, the corrected analytical model gives better results in evaluating the heating power using expression (32). We can observe that the relative difference doesn't exceed $7 \%$ at a speed of $1.2 \mathrm{~m} / \mathrm{s}$. Obviously, these results are coherent with the good predictions of the current density distributions presented in Figs.16 and 17.

\section{Time-Temperature curves}

The induction heater demonstrator doesn't fulfil any industrial constraints regarding the heating of aluminium billets. We only aimed to present the new heating concept together with its computationally efficient electromagnetic model which could be used in optimization procedures for rapid initial sizing. However, we have also performed temperature measurements in some locations of the device (workpiece and magnets). Thirteen K-type thermocouples (12 placed on the wotkpiece surface and 1 on the magnet surface) have been used to record the time-temperature data via a data acquisition card connected to a PC (see Fig. 5). 


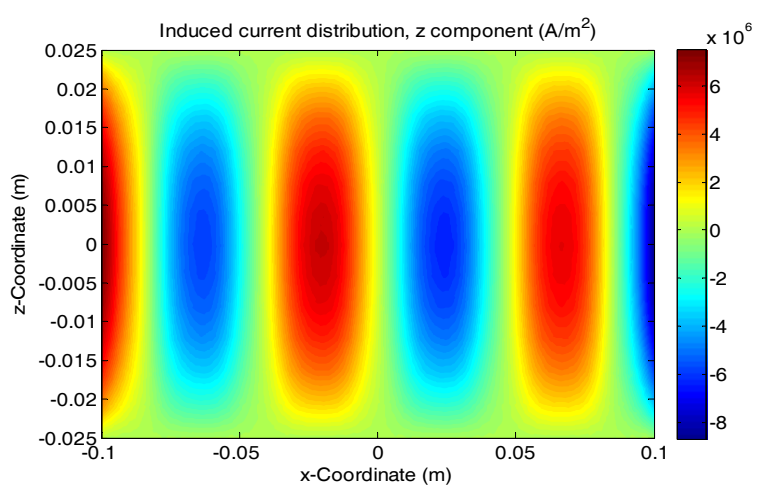

(a)

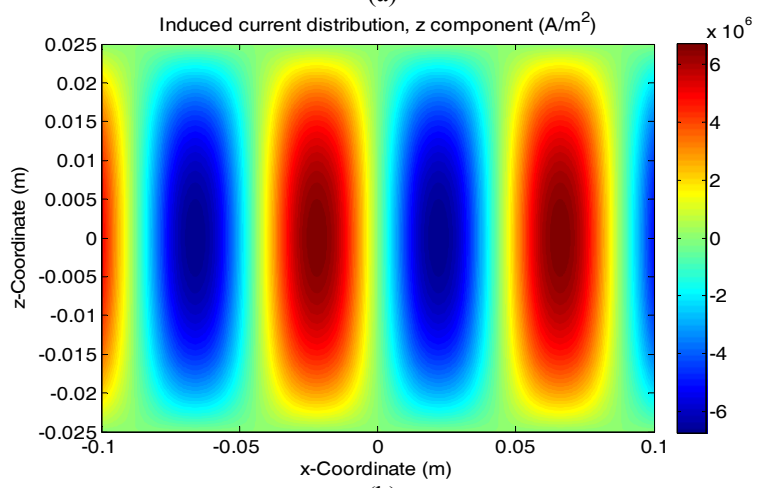

(b)

Fig.17. Induced current density distribution $J_{z}$ in $x z$ plane at the middle of the workpiece $(y=0)$ and $v_{\max }=1 \mathrm{~m} / \mathrm{s}$ : (a) 3D FEM, (b) Corrected analytical model

Figure 20 presents the measured time-temperature curves. It can be seen that the workpiece temperatures are almost the same and reach $230^{\circ} \mathrm{C}$ after 30 minutes. At the surface of the permanent magnets the measured temperature is $90^{\circ} \mathrm{C}$ which is far from the maximum operating temperature of the used magnets $\left(180^{\circ} \mathrm{C}\right)$.

At steady state (at time $t=100 \mathrm{mn}$ ), Fig. 21 illustrates the temperature distribution on the workpiece surface. The measurements are carried out by all the thermocouples $\left(\mathrm{T}_{1}\right.$ to $\mathrm{T}_{12}$ ) for a peak values $v_{\max }=1.18 \mathrm{~m} / \mathrm{s}$ of the workpiece velocity. We can observe that the temperature measured in surface conducting workpiece is sufficiently homogeneous.

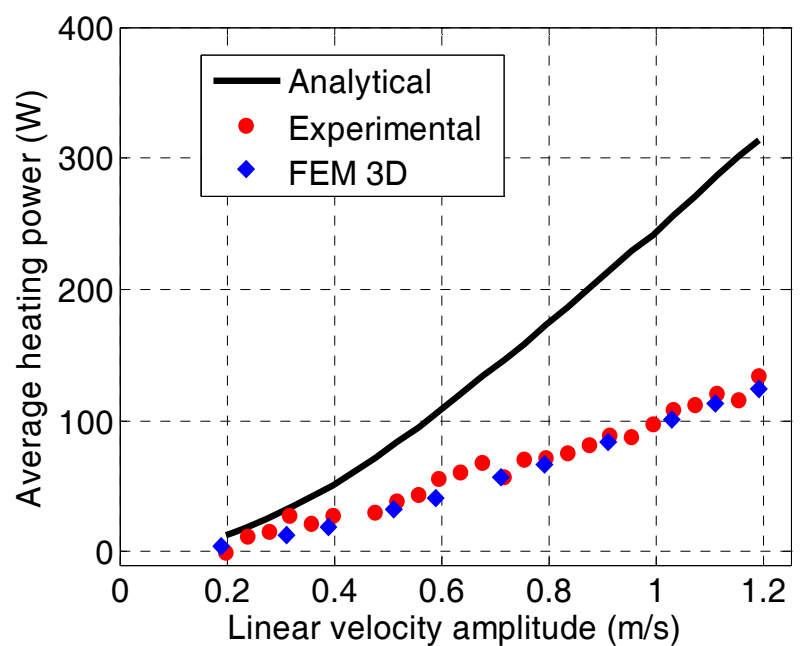

Fig.18. Average induced heating power versus peak value of linear velocity (without correction)

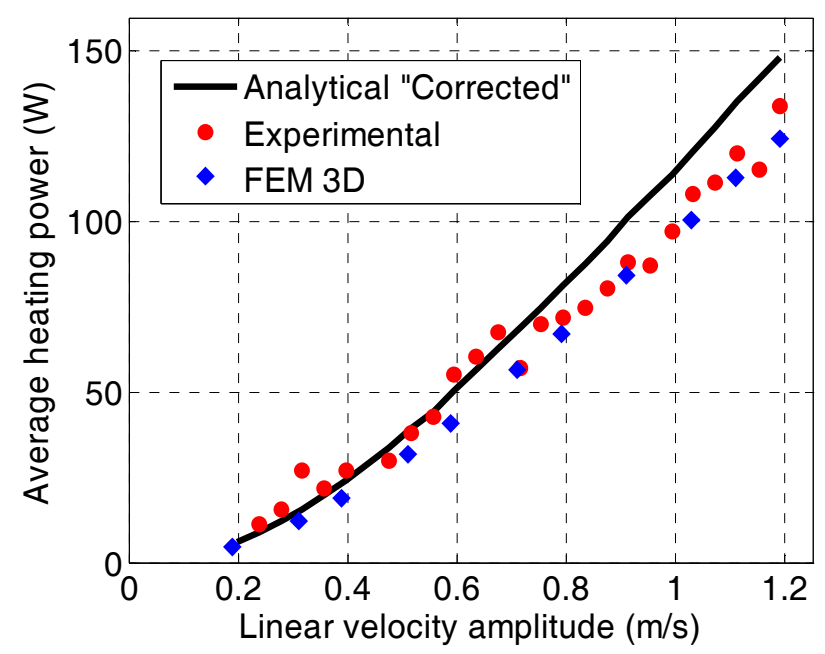

Fig.19. Average induced heating power versus peak value of linear velocity (with correction)

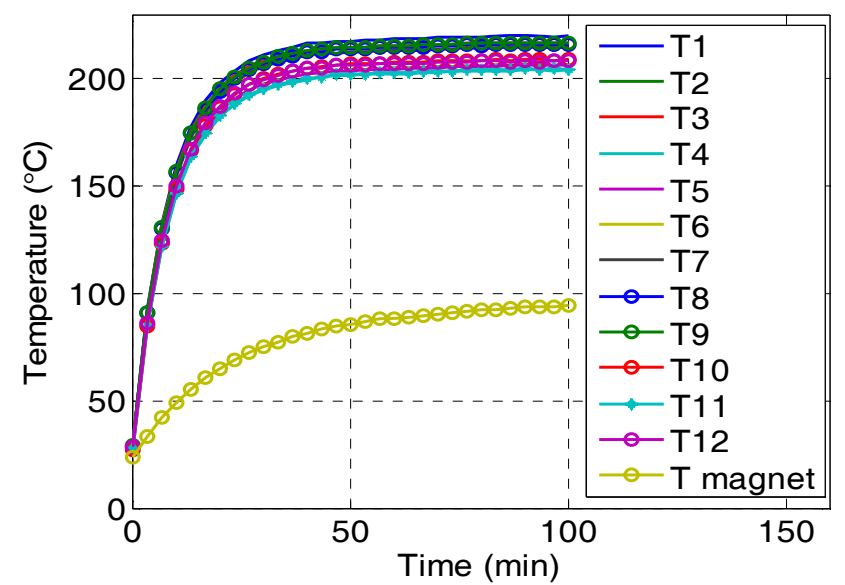

Fig.20. Temperature-time curves $v_{\max }=1.18 \mathrm{~m} / \mathrm{s}$ measured at different locations on the workpiece and magnet surfaces.

The work on the thermal aspects (thermal modelling, coupled magneto-thermal models, insulation issues...) are ongoing. Obviously, the built prototype together with all the measurement facilities will, hopefully, help us to validate the coupled electromagnetic-thermal models.

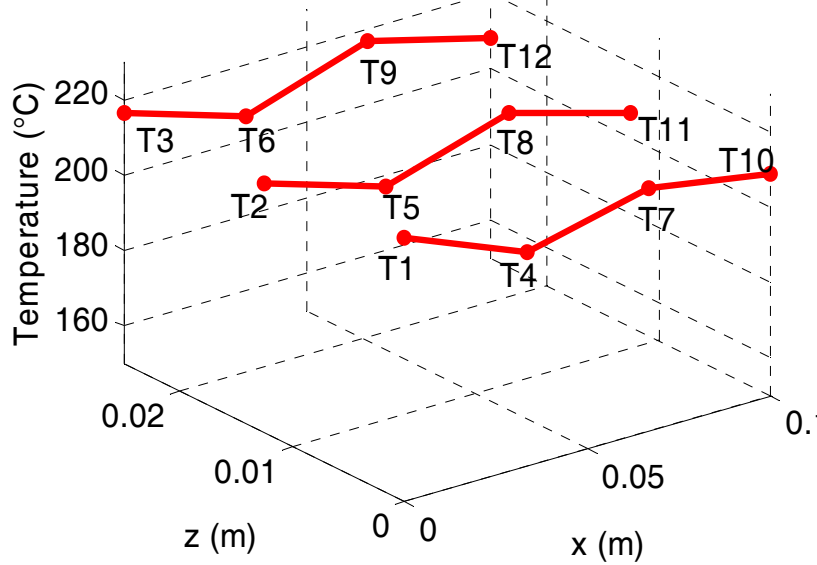

Fig.21. Temperature distribution on conducting workpiece surface measured by all thermocouples $\left(\mathrm{T}_{1}\right.$ to $\left.\mathrm{T}_{12}\right)$ for $v_{\max }=1.18 \mathrm{~m} / \mathrm{s}$ at time $t=100 \mathrm{~min}$ 


\section{CONCLUSION}

In this paper, we have presented a new structure of induction heater for aluminium parallelepiped workpiece. A spacevarying static magnetic field created by permanent magnets induces currents in the conducting workpiece subjected to an oscillatory linear motion.

An analytical model for the computation of the magnetic field distribution has been developed so heating power can be quickly evaluated. It has been shown that a correction of this model is necessary to take into account the transverse edge effects. For this purpose, we have introduced a correction factor of the electric conductivity, derived from another analytical model, to improve the accuracy of the developed analytical model.

A prototype of studied induction heater structure has been built and tested. Several mechanical, electromagnetic and thermal measurements have been carried out. The analytical predictions are in good agreement when compared to the experiments and to the 3D FE computations.

Hence, the presented electromagnetic model, coupled to some thermal models under development would constitute a robust tool for a rapid and accurate design of the studied heating system.

\section{APPENDIX}

\section{A. Field source model}

The development in Fourier series of the magnetization components can be written as

$$
\begin{gathered}
M_{x}(x)=\sum_{n=1,3,5, \ldots}^{\infty} M_{x n} \cos (n k x) \\
M_{y}(x)=\sum_{n=1,3,5, \ldots}^{\infty} M_{y n} \sin (n k x)
\end{gathered}
$$

where:

$M_{x n}$ and $M_{y n}$, are the peak value of the $n^{\text {th }}$ harmonic of the magnetization components, given by

$$
\begin{aligned}
& M_{x n}=\frac{4 B_{r}}{\mu_{0} n \pi} \sin \left(\frac{n \pi a}{\tau}\right) \\
& M_{y n}=-\frac{4 B_{r}}{\mu_{0} n \pi} \sin \left(\frac{n \pi b}{\tau}\right) \sin \left(\frac{n \pi}{2}\right)
\end{aligned}
$$

$\left(\tau=2(a+b)+4 e_{g}\right)$ is the spatial period, and

$k=\frac{2 \pi}{\tau}$ is the spatial pulsation.

\section{B. Magnetic vector potential expressions}

In conducting workpiece (Region 1), the general solution of (13), with $\frac{\partial \bar{A}_{1}}{\partial y}=0$ at $y=0$, has the following form

$$
\begin{aligned}
& \bar{A}_{1}(y)=\sum_{n=1,3,5, \ldots}^{\infty} \bar{a}_{1 n}\left(e^{\bar{\lambda}_{n_{1}} y}+e^{-\bar{\lambda}_{n_{1}} y}\right) \\
& \text { with: } \quad \bar{\lambda}_{n_{1}}=\sqrt{n^{2} k^{2}+j n k \sigma \mu_{0} v(t)}
\end{aligned}
$$

For region 2 where the electrical conductivity $\sigma=0$, the general solution is

$$
\bar{A}_{2}(y)=\sum_{n=1,3,5, \ldots}^{\infty}\left(\bar{a}_{2 n} e^{\lambda_{n_{2}} y}+\bar{b}_{2 n} e^{-\lambda_{n 2} y}\right)
$$

with: $\lambda_{n_{2}}=n k$

For region 3 where the electrical conductivity of permanent magnets is considered null, the general solution is

$$
\bar{A}_{3}(y)=\sum_{n=1,3,5, \ldots}^{\infty}\left(\bar{a}_{3 n} e^{\lambda_{n_{3}} y}+\bar{b}_{3 n} e^{-\lambda_{n_{3}} y}+\frac{\mu_{0} M_{y n}}{\lambda_{n_{3}}}\right)
$$

with: $\lambda_{n_{3}}=n k$

The complex coefficients $a_{1 n}, a_{2 n}, b_{2 n}, a_{3 n}$ and $b_{3 n}$ in (B.1), (B.2) and (B.3) are determined using the interface conditions between the different regions

at $y=y_{1}:\left\{\begin{array}{l}\bar{A}_{1}=\bar{A}_{2} \\ \frac{d \bar{A}_{1}}{d y}=\frac{d \bar{A}_{2}}{d y}\end{array}\right.$

at $y=y_{2}:\left\{\begin{array}{l}\bar{A}_{2}=\bar{A}_{3} \\ \frac{d \bar{A}_{2}}{d y}=\frac{d \bar{A}_{3}}{d y}-\mu_{0} M_{x n}\end{array}\right.$

at $y=y_{3}: \frac{d \bar{A}_{3}}{d y}=\mu_{0} M_{x n}$

\section{Transverse edge effect and corrected factor}

In the heated workpiece, the electromagnetic behaviour is described by the following equations

$$
\left\{\begin{array}{l}
\boldsymbol{\nabla} \times \boldsymbol{H}=\boldsymbol{J} \\
\boldsymbol{\nabla} \times \boldsymbol{E}=0 \\
\boldsymbol{J}=\sigma(\boldsymbol{E}+\boldsymbol{v}(\boldsymbol{t}) \times \boldsymbol{B})
\end{array}\right.
$$

Using the magnetic field $\boldsymbol{H}$, as state variable, we deduce from (C.1):

$$
\nabla \times \nabla \times H=\sigma \nabla \times(v(t) \times B)
$$

The eddy current components which result from (29) are then

$$
J_{x}(x, z, t)=\mathfrak{R}\left[\sum_{n=1,3,5 . .}^{\infty}-n k\left(\bar{c}_{1 n} e^{n k z}-\bar{c}_{2 n} e^{-n k z}\right) e^{j n k x}\right]
$$

$$
\begin{aligned}
& J_{z}(x, z, t)= \\
& \Re\left[\sum_{n=1,3,5 .}^{\infty} j n k\left(\bar{c}_{1 n} e^{n k z}+\bar{c}_{2 n} e^{-n k z}-j \frac{\sigma v(t) \hat{B}_{n}}{n k}\right) e^{j n k x}\right]
\end{aligned}
$$

The complex coefficients $c_{1 n}$ and $c_{2 n}$ are determined using the following conditions 


$$
\begin{aligned}
& \text { at } z=0, J_{x}=0 \rightarrow \bar{c}_{1 n}=\bar{c}_{2 n} \\
& \text { at } z=\frac{Z_{p}}{2}, J_{z}=0 \rightarrow \bar{c}_{1 n}=j \frac{\sigma v(t) \hat{B}_{n}}{n k\left(e^{\frac{n k Z_{p}}{2}}+e^{-\frac{n k Z_{p}}{2}}\right)}
\end{aligned}
$$

where, $Z_{p}$ is the workpiece width. When we consider an infinite workpiece width, only the $J_{z}$ component exists. This could be obtained by setting $Z_{p} \rightarrow \infty$ in (30) and (31)

$$
J_{x}=0 \text { and } J_{z}=\sum_{n=1,3,5, \ldots}^{\infty} \sigma v(t) \hat{B}_{n} \cos (n k x)
$$

The power heating created by $J_{z}$ is

$$
\begin{aligned}
& P_{0}=2 y_{1} Z_{p} \int_{\frac{-L_{p}}{2}}^{\frac{L_{p}}{2}} \frac{J_{z}^{2}}{\sigma} d x \\
& P_{0}=\sum_{n=1,3,5 \ldots}^{\infty} P_{0}(n)
\end{aligned}
$$

where $P_{0}(n)$ is the power heating induced by the $n^{\text {th }}$ harmonic of the current density

$$
P_{0}(n)=2 y_{1} Z_{p} \sigma v(t)^{2} \hat{B}_{n}^{2}\left[\frac{1}{2} L_{p}+\frac{\sin \left(n k L_{p}\right)}{2 n k}\right]
$$

On the other hand when the workpiece has a finite width (with transverse edge effect), the induced power heating $P_{0}$ becomes $P$ which is expressed as

$$
P=\frac{2 y_{1}}{\sigma} \int_{\frac{-L_{p}}{2}}^{\frac{L_{p}}{2}} \frac{\int_{-Z_{p}}^{2}}{2}\left(J_{x}^{2}+J_{z}^{2}\right) d x d z
$$

After integration, we obtain

$$
P=\sum_{n=1,3,5, \ldots}^{\infty} P_{0}(n)\left[1-\frac{\tau}{n \pi Z_{p}} \tanh \left(\frac{n \pi Z_{p}}{\tau}\right)\right]
$$

Now, we note:

$$
k_{\text {corr }}(n)=1-\frac{\tau}{n \pi Z_{p}} \tanh \left(\frac{n \pi Z_{p}}{\tau}\right)
$$

We can write

$$
P=\sum_{n=1,3,5, \ldots}^{\infty} k_{c o r r}(n) P_{0}(n)
$$

$k_{\text {corr }}(n)$ can be seen as a correction factor of the electric conductivity for the $n^{\text {th }}$ harmonic. This factor takes into account of the transverse edge effect in evaluating the induced power heating.

\section{REFERENCES}

[1] V. Rudnev, D. Loveless, R. Cook, and M. Black, "Handbook of Induction Heating", New York: Marcel Dekker, 2003.

[2] M. Fabbri, A. M. Forzan, S. Lupi, A. Morandi, and P. L. Ribani, "Experimental and numerical analysis of DC induction heating of aluminium billets," IEEE Trans. Magn., vol. 45, no. 1, pp. 192-200, Jan. 2009.

[3] T. Lubin, D. Netter, J. Leveque, and A. Rezzoug, "Induction heating of aluminium billet subjected to a strong rotating magnetic field produced by superconducting windings," IEEE Trans. on Magn., vol. 45, no 5, pp. 2118-2127, May 2009.

[4] F.Mach, V. Starman, P. Karban., I. Dolezel,and P. Kus, "Finite Element 2D Model of Induction Heating of Rotating Billets in System of Permanent Magnets and its Experimental Verification" IEEE Transaction on Industrial Electronics. Vol.61, №.5, May 2014.

[5] P. Karban, F. Mach, I. Dolezel, and J. Barglik, "Higher-order finite element modeling of rotational induction heating of nonferromagnetic cylindrical billets", COMPEL: The International Journal for Computation and Mathematics in Electrical and Electronic Engineering, vol. $30, n^{\circ}$ 5, p. 1517-1527, 2011.

[6] F. Mach, P. Karban, and I. Doležel, "Induction heating of cylindrical nonmagnetic ingots by rotation in static magnetic field generated by permanent magnets", ELSVIER, Journal of Computational and Applied Mathematics, vol. 236, $\mathrm{n}^{\circ}$ 18, p. 4732-4744, Dec. 2012.

[7] F.Mach, P. Karban., I. Dolezel, P. Sima, Z. Jelinek, "Model of Induction Heating of Rotating Non-Magnetic Billets and its Experimental Verification" IEEE Trans. on Magn vol.50, no.2, pp.309,312, February 2014.

[8] H. Bensaidane, Y. Ouazir, T. Lubin, S. Mezani, and A. Rezzoug, "Induction Heating of Aluminium Billets with linear motion in a Strong DC Magnetic Field: Magneto-Thermal Analysis in Two Dimensional", IEEE Transaction on applied superconductivity, Vol. 21, No. 4, pp 3479-3487, August 2011.

[9] T. Watanabe, T. Todaka, and M. Enokizono,"Analysis of a New Induction Heating Device by Using Permanent Magnets", IEEE Trans. Magn., Vol. 41, No. 5, p. 1884-1887, May 2005.

[10] J. Wang, H. Lin, S. Fang, and Y. Huang, "A general analytical model of permanent magnet eddy current couplings," IEEE Trans. Magn., vol. 50, no. 1, pp., Jan. 2014.

[11] S. L. Ho, Junhua Wang, and Y. H. Wang, "A novel crossed traveling wave induction heating system and finite element analysis of eddy current and temperature distributions," IEEE Trans. Magn., vol. 45, no. 10 , pp. 4777-4780, Oct. 2009.

[12] N. Esposito, M. Raugi, and A. Tellini, " Quasi analytical model for eddy currents and force in axisymmetric geometries with moving conductors," IEEE Trans. Magn., vol. 29, no. 6, pp. 2407-2409, Nov. 1993.

[13] R. L. Russell et K. H. Norsworthy, "Eddy currents and wall losses in screened-rotor induction motors", Proceedings of the IEE Part A: Power Engineering, vol. 105, $\mathrm{n}^{\circ}$ 20, p. 163, 1958.

[14] Q. Lu, Y. Li, Y. Ye, Z.Q. Zhu, "Investigation of Forces in Linear Induction Motor Under Different Slip Frequency for Low-Speed Maglev Application," Energy Conversion, IEEE Transactions on , vol.28, no.1, pp. 145,153 , March 2013

[15] I. Boldea, S. A. Nasar, "Linear Motion Electromagnetic Devices", Taylor \& Francis publications 2001.

[16] I. Boldea, S. A. Nasar, "The Induction Machine Handbook", CRC press 2002.

[17] J. P. Decreux and G. Nicolas, "Finite length effects study in massive iron rotors using 3D electromagnetic field computation," IEEE Trans.Magn., vol. 31, no. 3, pp. 2096-2099, May 1995. 
Hakim Bensaidane was born in Tizi-Ouzou, Algeria, in 1977. He received the Engineer diploma and the Magister degree from the University Mouloud Mammeri of Tizi-Ouzou, Algeria, in 2003 and 2006, respectively, and the Ph.D. degree from the University of Science and Technology Houari Boumediene, Algiers, in 2013.

$\mathrm{He}$ is currently a Lecturer and a member of the Laboratoire des Systemés Electriques et Industriels, University of Science and Technology Houari Boumediene, Algiers, Algeria. His research interests include numerical and analytical modeling of electromechanical devices, coupled magnetic and thermal problems and applied superconductivity in induction heating devices.

Thierry Lubin was born in Sedan, France, in 1970. He received the M.S. degree from the Université Pierre et Marie Curie-Paris 6, Paris, France, in 1994, and the Ph.D. degree from the Université Henri Poincaré, Nancy, France, in2003. $\mathrm{He}$ is currently a Lecturer of electrical engineering in the Groupe de Recherche en Electrotechnique et Electronique de Nancy, Université Henri Poincaré, Vandoeuvre-lès-Nancy, France. His interests include modeling and control of electrical machines and applied superconductivity in electrical devices.

Smail Mezani received the Dipl.-Ing. and Magister degrees in electrical engineering from the University of Sciences and Technology Houari Boumediene, Algiers, in 1996 and 1999, respectively, and the Ph.D. degree from the Institut National Polytechnique de Lorraine, Nancy, France, in 2004. $\mathrm{He}$ is a Lecturer of Electrical Engineering with the Faculty of Sciences and Technology, University of Lorraine, Nancy, where his research works are undertaken in the Groupe de Recherche en ' Electrotechnique et ' Electronique de Nancy Laboratory. He was on secondment from the University of Lorraine, working at the Power Electronics, Machines, and Control (PEMC) Group, University of Nottingham, U.K., on magnetically geared induction machines in the frame of a Marie-Curie Intra European Fellowship. His research interests include numerical and analytical modeling of electrical machines and contactless torque transmissions, coupled magnetic and thermal problems, and the applications of superconductors in electromechanical devices.
Youcef Ouazir was born in Setif, Algeria, in 1970. He received the Engineer diploma, the Magister and Ph.D. degrees from the Ecole Nationale Polytechnique d'Alger, Algiers, Algeria, in 1994, 1997, and 2006, respectively. After working as lecturer until 2011, he is actually a Professor of electrical engineering, head of the electrical engineering department and a member of the Laboratoire des Systèmes Electriques et Industriels, at the University of Science and Technology Houari Boumediene (USTHB), Algiers. His research interests include modelling of electromechanical devices, field computation methods, coupled problems.

Abderrezak Rezzoug received the Electrical Engineer degree from the École Nationale Supérieure d'Électricité et de Mécanique, Nancy, France, in 1972, and the Dr. Ing. diploma and the Ph.D. degree from the Institut National Polytechnique de Lorraine(INPL), Vandoeuvre-lès-Nancy, France, in1979 and 1987 , respectively.

After working with INPL as an Assistant Professor until 1991, he joined the Université Henri Poincaré, Vandoeuvre-lèsNancy, where he is currently a Professor of electrical engineering and a member of the Groupe de Recherche en Electrotechnique et Electronique de Nancy. His main areas of research concern superconducting applications to electrical devices, as well as the control and diagnosis of electrical machines 